\title{
Immigration and Trust in Politics in Britain
}

\author{
Lauren M. McLaren \\ Associate Professor of Politics \\ University of Nottingham \\ School of Politics and International Relations \\ Nottingham NG7 2RD \\ United Kingdom \\ e-mail: lauren.mclaren@nottingham.ac.uk \\ Phone: +44 (0) 1158467511 \\ Fax: +44 (0) 1159514859
}

Forthcoming in the British Journal of Political Science.

\footnotetext{
This research was conducted with the support of British Academy Research Development Award 52926. The author thanks the Academy for its support for this research. A previous version of this paper was presented at the seminar, 'The Role of the Electorate in Selecting Minority Candidates: Public Opinion and Electoral Preferences', Department of Sociology, University of Oxford, 13 April 2010. The author thanks the conference participants, as well as four anonymous reviewers for their helpful comments on the paper. Any errors are the sole responsibility of the author.
} 


\section{Immigration and Trust in Politics in Britain}

Abstract

This paper argues that a previously overlooked explanation for varying individual-levels of political trust is concern about immigration. Focusing on the case of Britain, where levels of opposition to immigration have remained high since the 1960s and yet the implications of such opposition are still unclear, this paper examines the effect of concern about immigration on political trust. Using the pre- and post-election panel component of the 2005 British Election Study and the 2002-3 European Social Survey, we illustrate that after controlling for a wide range of other predictors of trust in politics, concerns about the impact of immigration significantly affect political trust. In addition, in 2005 the perception that government had not handled the issue of immigration effectively also significantly affected political trust, with both linear and interactive effects. 
In the decades since the end of the Second World War, one of the most pressing and divisive issues that has come to dominate the political agendas of western democracies is immigration, with most European publics expressing unease with migration to their countries. However, the range of potential implications of concern about immigration are not very well known. In some European countries, one of the most obvious implications is the rise of extremist, anti-immigration parties; this paper considers another potential consequence of public concerns about immigration, reduced political trust. Specifically, focusing on the British case where the consequences of concern about immigration are less obvious than in many other European countries, the paper examines the relationship between concern about immigration and trust in politics. ${ }^{1}$ Determining whether such a connection exists is important because trust in politics is thought to be crucial to effective policymaking and compliance with government regulations. ${ }^{2}$ It is also important because many conceptualizations of system support include notions of community, ${ }^{3}$ particularly positive orientations of citizens toward one another and toward political elites and the political system. Thus, understanding what produces trust and distrust is important, as is understanding how perceptions of newcomers affect feelings of political community generally. Although we have some understanding of the causes of political distrust, this paper contends that an additional piece of the puzzle of public distrust may be immigration, and particularly perceptions that migration is undermining the national community on which many believe democratic political institutions were built. The implications of the paper's findings are of considerable importance because they point to the conclusion that rather than being an inconsequential sentiment in a country like Britain, the consequences of public worries about immigration are 
potentially very serious indeed, in that such concern is likely to be one of the forces undermining trust in the British political system, and thus feelings of political community more generally.

The next section conceptualizes the dependent variable in this study-political trust — and outlines why concerns about migration are likely to be related to political trust; the section ends by proposing three specific hypotheses. The following section then explains why the British case is of particular interest and tests the proposed hypotheses using the panel component of the British Election Study of 2005. These results are compared to the 2002-3 European Social Survey. The latter is then further explored using an instrumental variables approach. The findings from all of these analyses provide support for the main contention of this paper: concerns about immigration do appear to be undermining the functioning of the British political system by reducing levels of political trust.

\section{Political Trust, Identity and Immigration}

This paper is concerned with the relationship between perceptions of immigration and perceptions of the political system, particularly political trust. This section outlines what is meant by 'political trust' in this paper and then discusses reasons why concern about immigration is likely to explain some of the variation in political trust. It then presents three specific hypotheses about the relationship between concern about immigration and political trust before proceeding to test these in the next section of the paper.

\section{Political Trust}


For some scholars, expressions of trust in a political institution are declarations that on average the agents operating within those institutions will prove trustworthy ${ }^{4}$ or that the democratic institutions serve to select relatively trustworthy agents. ${ }^{5}$ Miller and Listhaug argue that political trust 'is a summary judgment that the system is responsive and will do what is right even in the absence of constant scrutiny'. ${ }^{6}$ David Easton highlighted the importance of political community in maintaining stable political systems, arguing that political systems are thought to be prone to failure if political community is lacking - that is, if individuals in the system are not 'sufficiently oriented toward one another' and willing to support the existence of a group of individuals who can negotiate and settle differences. ${ }^{7}$ That is, amongst other things, stable political systems rely on a basic level of interpersonal connection and trust as well as some degree of trust in elites and institutions running the system. As will be explained below, it is our contention that immigration is likely to pose problems for this notion of political community, thereby potentially undermining support for the political system.

Also of relevance here is Easton's distinction between diffuse and specific system support. ${ }^{8}$ Easton conceptualizes diffuse support as a deep-seated set of attitudes toward politics and the political system that is relatively impervious to change. On the other hand, specific support is related to the actions and performance of government or political elites. The assumption is that short-term policy failures should not directly erode diffuse regime support or support for the political community as a whole.

While this conceptual distinction may seem fairly clear, measuring diffuse versus specific support for the political system is less than straight-forward. When we ask citizens whether they have trust or confidence in their national parliaments, presidencies, 
or governments, are we measuring their attitudes to the current set of leaders and policies or more general orientations to these institutions and elites? ${ }^{9}$ Comparative analyses of survey questions pertaining to attitudes to government indicate that while there is overlap in individual-level perceptions of current authorities and attitudes to other aspects of the political system-e.g., its institutions—-perceptions of institutions appear to be empirically distinct from perceptions of current government officials. ${ }^{10}$

This paper is especially concerned with general orientations to political institutions and elites, and assumes — based on the above-mentioned comparative analyses — that indicators of trust and confidence can validly tell us something meaningful about these general orientations. Given that such items are, in fact, likely to tap into both types of support, in order to try to reduce the likelihood that our findings solely pertain to specific support, we (a) include multiple indicators of political trust; (b) control for known strong predictors of specific support; and (c) investigate the effects of concern about immigration on attitudes to the political system across multiple surveys.

\section{The Relationship Between Concern About Immigration and Political Trust}

Most international relations scholars would argue that modern states-particularly modern European states-were built upon notions of shared identity and values. Some scholars believe that the creation of common identity resulted from modern advances in transportation and printing, both of which are fairly important for the creation of a common language, which is, in turn, important for the articulation of common values across a large territory. ${ }^{11}$ Others believe there may have also been an active attempt on the part of state leaders to construct such an identity. ${ }^{12}$ Still others contend that common 
identity across large territories originates from a primordial human need for connection, and that modernization produced a transposition of notions of family (and particularly super-family) onto others living within state territory. ${ }^{13}$ Many of these hypotheses imply a considerable amount of artificiality in the construction of national identities. Anthony Smith, however, contends that although the creation of the modern nation-state was made possible by economic and bureaucratic modernization (and particularly one key component of modernization-mass education), 'the presence of a core ethnie around which strong states could be built' made the creation of nations possible. ${ }^{14}$ That is, such states have been built around shared cultural heritage and norms. ${ }^{15}$ Evidence also indicates that these identities, including their civic, ethnic and cultural components are still extremely relevant to citizens of European countries, including Britain. ${ }^{16}$ Moreover, research on social identities has long pointed to the conclusion that identities—even artificially constructed laboratory-based identities_-are meaningful to individuals because they contribute positively to self-esteem and self-image and because they help to provide clarity in a complex, confusing world. ${ }^{17}$ The inference is therefore that longestablished identities like national identities are even more relevant and powerful, no matter how artificial they may appear to the outside observer. Immigrants pose clear threats to these identities by bringing with them seemingly different values and ways of life; they are also perceived to threaten the economic resources of fellow countrymen and -women. ${ }^{18}$ Particularly in countries like Britain in which the main myths of identity have not tended to include the myth of being accepting of migrants (compared to the myths of identity in the United States, for instance ${ }^{19}$ ), it may be unclear to many citizens as to how to reconstruct identity to incorporate newcomers. Newcomers who may be 
perceived as holding extremely different values from those of natives-Muslim migrants vis-à-vis a predominantly secular Britain, for instance_-may be particularly difficult to reconcile with existing national identities.

The difficulty of coming to terms with new migrants, in turn, has potential implications for political systems. As noted above, political systems are thought to be prone to failure if there is an absence of political community-to reiterate, if individuals in the system are not 'sufficiently oriented toward one another' and willing to support the existence of a group of individuals who can negotiate and settle differences. ${ }^{20}$ Some research into social capital has already come to the conclusion that immigration and multiculturalism may create problems for the former of these conditions (i.e., orientation toward one another), although it must be noted that the evidence is somewhat mixed. ${ }^{21}$ Immigration, and more specifically, perceptions of migration, may also create problems for the latter-i.e., the willingness to support the existence of a group of individuals who can engage in policymaking — and reduce willingness to support the institutions through which these groups of elites govern. This is because feelings of disunity are not likely to apply solely to feelings of citizens for one another but are also likely to stretch to feelings about the elites in this community and the way the community is governed as well. Indeed, evidence indicates that individuals tend to be increasingly less favourable toward using the institutions of the state to reduce poverty and provide welfare as a result of perceptions of cultural differences between groups who access these services. ${ }^{22}$ Moreover, systems like the British political system and its notions of political equality are argued to have been layered onto pre-existing cultural connections; ${ }^{23}$ a perceived 
weakening of these cultural connections because of immigration is also likely to subsequently weaken attachment to this political system.

In short, it is clear that immigration creates widespread concern about political and social community and about social identities. Moreover, under pre-massimmigration conceptualizations of national identity, the institutions through which elites governed the national polity were designed to govern and adjudicate between members of the national community. When individuals perceive that immigration has threatened that community the institutions that govern them are likely to be called into question. That is, those most attuned to the effects of immigration on the national community may question the extent to which national political institutions exist to represent a national citizenry. Moreover, it is likely that individuals specifically blame their political elites and institutions for allowing large-scale migration in the first place and thus hold these elites and institutions in contempt as a result. While some of the prior research discussed above hints at the connection between immigration and perceptions of political systems, there is not yet an investigation of this relationship. The analysis here takes a first step in filling this gap. We examine three specific micro-level propositions regarding the relationship between immigration and trust in politics:

Hypothesis 1 Those expressing most concern about the impact of immigration on the national community will be least trusting of politicians and political institutions.

Hypothesis 2 Those who believe the government has done a poor job of handling immigration will be least trusting of politicians and political 
institutions.

Hypothesis 3 The relationship between concern about immigration and perceptions of government handling of immigration will be interactive: those who are most concerned about immigration and believe the government has handled the immigration issue poorly will be the least trusting of politicians and political institutions. ${ }^{24}$

\section{Immigration and Political Trust in Britain: The Analysis}

As mentioned above, in many European democracies, one of the most obvious results of large-scale immigration has been expression of anti-immigration sentiment via extremist parties such as the Front National in France, the Party for Freedom in the Netherlands (and in the 2002 and 2003 elections, Lijst Pim Fortuyn), or the Freedom Party in Austria and the more extreme Freedom Party breakaway party, the Alliance for the Future of Austria. In these cases, immigration-related concerns gain some expression in the 'legitimate' political institutions by achieving representation in these institutions, including becoming part of governing coalitions. The UK political system, in contrast, provides very few institutional outlets for the expression of concern about immigration, despite the fact that anti-immigration is fairly strong there.

For instance, even as early as the 1960s, roughly 85 per cent of British citizens felt that too many immigrants had been let into the country. ${ }^{25}$ In the 1990 s, approximately 65 per cent in Britain thought that immigrants abused the system of social benefits and that schools suffered where there were more immigrants. ${ }^{26}$ The 2003 British Social Attitudes Survey indicated that 75 per cent of respondents were in favour of 
increased immigration restrictions, while the 2008 British Social Attitudes Survey indicated that 65 per cent of Britons believed immigration was a threat to their national identity. ${ }^{27}$ Ipsos/Mori poll data also indicate that since the late 1980 s a majority in Britain think too many migrants have been let into the country. ${ }^{28}$ In the 2009 Transatlantic Trends: Immigration survey, more than 60 percent of Britons stated that immigration was more of a problem than an opportunity, the highest of all countries included in the survey (the other countries were France, Germany, Italy, Canada, U.S., Netherlands, and Spain). The highest percentages of individuals claiming that immigrants take jobs from the native born and that immigration negatively affects national culture were found in Britain in that survey as well, and similar percentages were noted in the 2008 version of this survey. ${ }^{29}$ Although it was traditionally assumed that Britain had less difficulty in reconciling immigration with national identity because British identity was predominantly civic in nature, evidence indicates that British identity also still has strong ethnic and cultural components, ${ }^{30}$ which make inclusiveness toward immigrants and immigration extremely difficult. In addition, while level of concern about immigration has always been high amongst the British public, the past decade has witnessed even larger-scale net migration to the UK, including a rise in the numbers of asylum seekers, along with rising uneasiness with Muslim migrants and minorities. ${ }^{31}$ Thus, for the reasons discussed in the previous section, it seems very likely that such concerns would have a considerable impact on perceptions of the functioning of the British political system.

However, while parties like the BNP and UKIP attempt to attract votes on the basis of public concern about immigration, most voters in the UK will not vote for either 
of these parties in general elections, presumably because they realize neither of these parties has any realistic chance of winning enough votes to win even a single parliamentary constituency, much less enough seats to take part in government (although it must be noted that this could change if there is large-scale reform of the electoral system, as proposed by the current governing coalition). Although the BNP had begun to make some headway in local government elections in places like Yorkshire, Lancashire, and East London as well as in the 2009 European parliamentary elections, despite fielding an unprecedentedly large number of candidates in the 2010 general elections the party still failed to win even a single seat in the national parliament and only attracted 2.1 per cent of the popular vote, an increase of 1.2 percentage points on the 2005 general election.

In addition, while mainstream centre-right parties in other parts of Europe have provided an additional outlet for anti-immigration sentiment by co-opting the platform and rhetoric of the far-right (as is the case periodically in France, for instance), in the UK the two dominant political parties have often held relatively similar policy positions on immigration, making it difficult for citizens to vote on this particular issue. ${ }^{32}$ Specifically, both major parties have traditionally claimed to want to stem the flow of migration to the UK while simultaneously supporting policies to protect those already in the UK from discrimination. ${ }^{33}$ Thus, distinguishing between the two parties on the issue of immigration may at times pose some difficulty for British citizens. Also of importance is that both parties appear to be somewhat divided on the issue of immigration, with former Labour officials such as David Blunkett previously speaking fairly negatively about immigration and immigrants ${ }^{34}$ and more recently Frank Field, 
Margaret Hodge, John Denham, Jon Cruddas, and Anne Cryer (amongst others) engaging in 'tough talk' on immigration, on the one hand, and Conservative party members expressing unease over the introduction of immigration or race into party rhetoric, on the other-although it must be noted that Labour is more internally divided over this issue than the Conservatives. ${ }^{35}$ Even when the issue is specifically introduced by the Conservative Party in an election - as in 2005-it appears that other variables, such as leadership qualities and performance on policies other than immigration, are likely to be more important in explaining vote choices. ${ }^{36}$ This paper suggests that while immigration-related worries may have a limited impact on electoral outcomes in Britain, they may still affect the British political system by reducing trust in British politicians and political institutions for the reasons noted above: immigration is perceived as weakening the connection between citizen, on the one hand, and institutions and politicians, on the other, because of perceived threat to national community. Moreover, as also noted above, politicians and institutions are likely to be blamed for failing to adequately control immigration. ${ }^{37}$

\section{Analysis 1: The 2005 British Election Study (BES)}

As discussed above, we are interested here in perceptions of the political system as a whole and thus examine trust in multiple components of this system. In particular, we incorporate an indicator of trust in the key elected political institution in Britain, the national parliament. We also include an indicator of trust in politicians. In addition, we include an indicator of trust in an unelected institution, the police. Because these items are strongly connected to one another and scale very well and because prior research 
also indicates that they ought to be strongly connected to one another, ${ }^{38}$ they have been combined into a single index of political trust, which ranges from $0-10$, with high values representing higher levels of political trust (see Appendix A for question wording and scaling information). It was also expected that the combination of items would capture the systematic diffuse support component of political trust. It should be noted, though, that we have also examined the predictors of each item individually and the results are very similar to those reported below; that is, on the whole, the predictors of trust in the elected institution (parliament) and elected individuals are similar to the predictors of trust in our unelected body, the police, indicating that the findings are likely to pertain to general system support rather than solely to specific support for particular incumbents.

Prior research on perceptions of political systems and incumbents points to a wide range of potential explanations for individual-level differences in these perceptions, which we incorporate here. Echoing the major 1980s and 1990s electoral studies' refrains of 'It's the Economy, Stupid' and drawing on Easton's model of the political system in which (perceived) outputs of the system are likely to produce shortand long-term effects on perceptions of the system as a whole, many researchers have pointed to the role of economics in explaining differences in individual-level and aggregate-level perceptions of political institutions and incumbents. Thus an economy that is performing poorly or perceptions that the national economy or one's own personal economic circumstances are declining (or are likely to decline) have all been argued to affect attitudes to political institutions and politicians, at least in the shortterm. ${ }^{39}$ Perceptions of the functioning of political institutions are also important: if governments are perceived to be fair and open, if politicians can be held accountable, 
and if individuals perceive governments to be performing well along various policy dimensions, individuals are more likely to have favourable attitudes to political institutions and elites, again, at least in the short-term. ${ }^{40}$ Thus, levels of trust in politics are likely to be connected to the manner in which institutions function and whether citizens perceive governments to be performing well. More recently, scholars have linked distrust in politics to social capital, including voluntary and other informal participatory networks and interpersonal trust. ${ }^{41}$ This paper does not attempt to analyze the causality of this relationship, but simply introduces controls for social capital in the multivariate models below. Analyses also point to the effects of being electoral 'losers'-i.e., voting for a party that fails to get into government-and indicate that electoral losers may lose some degree of confidence in the political system in the shortterm. ${ }^{42}$ The analysis below incorporates these potential explanations of variation in system support. As discussed above, it is expected that with these several indicators of specific support included in the model-particularly winning and losing, perceptions of government handling of specific policy areas, and perceptions of the economy-at least some of the remaining covariation between concerns about immigration and political trust is likely to be relevant to diffuse support.

This paper makes strong claims about the impact of immigration on trust in British politics. Because of the strong claims being made, our primary aim in the analysis is to make the tests of our propositions as difficult as possible so that any evidence found in support of these propositions will be robust. We have tried to ensure robustness by introducing the strong controls noted above. We also investigate our propositions specifically using the British Election Study of 2005, which includes a short 
panel component. We take advantage of this panel component of the 2005 BES in order to help reduce the likelihood of (a) spurious relationships and (b) potential endogeneity problems. First, we incorporate a lagged dependent variable- that is, the respondent's level of political trust at $t-1$, which is measured in the BES pre-election survey conducted between February and April $2005{ }^{43}$ This variable should help to reduce omitted variable bias, providing a control for any predictors of political trust that are not controlled for via other independent variables. Second, our indicators of concern about the impact of immigration and perceptions of government handling of immigration will be measured at $t-1$ while all other controls (perception of government handling of other policy areas, economic perceptions, etc.) will be contemporaneous. With the incorporation of a lagged dependent variable and lagged expressions of concern about immigration and perceptions of government handling of immigration, any significant relationship that is found is highly likely to run in the hypothesized direction rather than the reverse (that is, concern about immigration predicts political trust rather than the reverse). Thus, because of the desire to control for lagged level of trust and for the many controls mentioned above, the 2005 BES is the best available recent data set for conducting this analysis.

We begin by estimating the simple model of:

Political Trust $_{t}=\beta_{0}+\beta_{1}$ Political Trust $_{\mathrm{t}-1}+\beta_{2}$ Concern about Immigration $_{\mathrm{t}-1}+$ $\beta_{3}$ Perception of Government Handling of Immigration ${ }_{t-1}+\beta_{4}$ Concern about Immigration $_{\mathrm{t}-1} *$ Perception of Government Handling of Immigration $\mathrm{t}_{\mathrm{t}-1}+e_{i}$

(Equation 1) 
That is, political trust as measured in the post-election study will be predicted by political trust in the pre-election survey, concern about immigration in the pre-election survey, perceptions of government handling of immigration, also in the pre-election survey, and the interaction between the latter two. We have incorporated two separate indicators of concern about the impact of immigration-one of these measures concern about the effect of immigration on culture and the other measures concern about impact of immigration on natives' jobs. ${ }^{44}$ Appendix A provides the question wording for these variables and Table 1 provides the estimates of coefficients for Equation 1.

[Table 1 about here]

Model 1 tests Hypotheses 1 and 2 and the results indicate that concern about the impact of immigration on culture and perceptions of government handling of immigration both have independent effects on political trust. Concern about the impact of immigration on the jobs of natives appears to have no statistically significant effect on political trust. Given that our argument about the relationship between immigration-related worries and political trust revolved around notions of shared national culture, it is perhaps unsurprising that it is such concerns that have an impact on political trust. It is worth reiterating that the effects reported in Table 1 are the effects of concern about immigration and perceptions of handling of immigration by government even after including a lagged dependent variable in the model, and using lagged levels of concern about immigration. Model 2 of Table 1 tests the interactive effect of Hypothesis 3 and the results also provide support for this hypothesis. Again, the effect is only present for 
concern about the impact of immigration on culture, not jobs. We revisit this relationship below.

As discussed above, in order to help further ensure robustness, we control for the wide range of variables found to be related to attitudes to the political system or its incumbents in previous literature which were outlined briefly above: retrospective and prospective personal and national economic evaluations, evaluations of government performance across several policy areas (crime, health service, terrorism, the economy, and taxation), social capital (interpersonal trust and participation in voluntary organisations), and loser versus electoral winner status. Following the work of Anderson $^{45}$ and Rohrschneider ${ }^{46}$, we also incorporate controls for education, age, gender, and income. ${ }^{47} \mathrm{We}$ introduce an additional control for left-right self-placement as an indicator of general ideological predisposition, as this is likely to be connected to both attitudes toward immigration and distrust of national political institutions, with those identifying with the far-right being most hostile toward immigration and toward national political institutions. Dummy variables are also included for Scotland and Wales. Note that all of these variables are measured contemporaneously, and thus our lagged independent variables will be competing against these contemporaneous measures. Again, this is done to help ensure a high level of robustness if the immigration-political trust relationship finds empirical support. In addition, the 2005 election took place at a time of heightened concern about Britain's involvement in Iraq and so we control for approval of involvement in the war. ${ }^{48}$ Furthermore, as outlined above, the model incorporates a lagged dependent variable-that is, self-reported level 
of trust in the two institutions and politicians in the pre-election survey. Measures of all variables are provided in Appendix A, and the equation we estimate is as follows:

Political Trust $_{t}=\beta_{0}+\beta_{1}$ Political Trust $_{\mathrm{t}-1}+\beta_{2}$ Concern about Immigration $_{\mathrm{t}-1}+$ $\beta_{3}$ Perception of Government Handling of Immigration ${ }_{t-1}+\beta_{4}$ Concern about Immigration $_{\mathrm{t}-1} *$ Perception of Government Handling of Immigration $_{\mathrm{t}-1}+\beta_{5}$

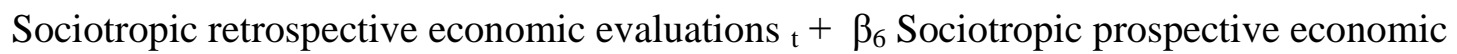
evaluations $_{t}+\beta_{7}$ Pocketbook retrospective economic evaluations ${ }_{t}+\beta_{8}$ Pocketbook

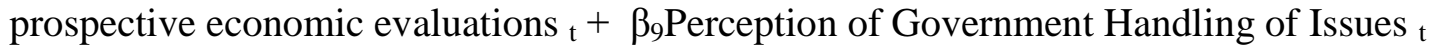
$+\beta_{10}$ Interpersonal Trust ${ }_{\mathrm{t}}+\beta_{11}$ Participation in Voluntary Activities ${ }_{\mathrm{t}}+\beta_{12}$ Voted for Party Other than Labour ${ }_{t}+\beta_{13}$ Voted BNP $_{t}+\beta_{14}$ DidNotVote $_{t}+\beta_{15}$ Education $_{t}+$ $\beta_{16}$ Age $_{\mathrm{t}}+\beta_{17}$ Female $_{\mathrm{t}}+\beta_{18}$ Income $_{\mathrm{t}}+\beta_{19}$ Left-right self-placement $_{\mathrm{t}}+\beta_{20}$ Scotland $_{\mathrm{t}}+$ $\beta_{21}$ Wales $_{\mathrm{t}}+\beta_{22}$ IraqApproval $_{\mathrm{t}}+e_{i}$ (Equation 2)

Table 2 provides the coefficients for this equation, and these generally confirm the findings from the simple models in Table 1. That is, concern about the impact of immigration on culture, perceptions of government handling of immigration, and the interaction between these variables all appear to be statistically significant predictors of political trust. Figure 1 provides a graphical representation of the relationship between immigration concerns, perception of government handling of immigration, and political trust. ${ }^{49}$ The graph indicates that the impact of perceptions of government handling of immigration on political trust is stronger for those who believe immigrants have not contributed to British culture, while for those who believe immigrants have contributed 
to culture, the impact of perceptions of government handling of immigration is very limited. As noted above, the reported effect of the former is based on lagged indicators of these independent variables and incorporates a control for lagged level of political trust. Figure 2 also illustrates the marginal effects of concern about immigration on political trust, depending on the level of perceived mishandling of immigration by government, including the standard errors around these effects. ${ }^{50}$ The bands around the effects line indicate that we cannot have as much confidence in the effects at the highest levels of perceived government mishandling of immigration but the illustrations generally provide support for the interactive hypothesis. It is also worth noting that even without the interaction, concern about the impact of immigration on culture and perceiving government to have mishandled the issue were both independently related to political trust (i.e., in the non-interactive model). Thus, the evidence seems to suggest that perceptions of immigration are indeed affecting perceptions of government institutions and officials. It is also important to note that the relationship between attitudes to the impact of immigration on culture and perception of government handling of immigration on political trust was roughly similar across the three indicators of the dependent variable to the results reported here. That is, the interaction between concern about immigration and perception of poor handling of immigration appears to affect perceptions of the unelected institution, the police, as well as perceptions of parliament and politicians, again lending support to the notion that the relationship found here pertains to general system support.

[Table 2 and Figures 1 and 2 about here] 
Immigration-related concerns are, of course, not the only strong predictors of political trust. Perceptions of government handling of other issues, economic evaluations, interpersonal trust, left-right self-placement, and approval of Britain's involvement in Iraq, as well as being an electoral loser, also predict political trust. However, the immigration variables are amongst the stronger predictors, despite not being measured contemporaneously. These findings support the propositions raised above: that worries about the impact of immigration on national culture and blaming the government for allowing increased immigration combine to create a group of citizens who are distrustful of their politicians and political institutions. Further implications of these findings will be discussed in the conclusion.

We have also analyzed the relationship between concern about immigration, perceptions of mishandling of immigration, and respect for politicians and political institutions using the 2001 British Election Study (analysis not shown). ${ }^{51}$ In some ways the results mirror those from the 2005 survey; namely, of the two indicators of concern about immigration, only concern about the cultural impact of migration achieves statistical significance by usual social science standards (i.e., $\mathrm{p} \leq 0.05$ ). In addition, the size of the effect of this variable on respect for politicians and institutions was somewhat larger than that in the 2005 analysis, with an unstandardized coefficient more than twice the size of the coefficient in the 2005 analysis. On the other hand, the impact of perceptions of government handling of immigration on respect was not statistically significant in the multivariate model. Thus, in 2001 perceptions of mismanagement of immigration did not yet translate into negative perceptions of institutions and politicians. 
Moreover, there was no apparent interactive effect in 2001. Thus the multivariate analyses based on the 2001 election survey results appear to indicate that concern about the impact of immigration was having an effect on attitudes to politicians and institutions in 2001, but that perceptions of government mishandling of migration were not yet playing a significant role in predicting attitudes to politicians and institutions. ${ }^{52}$

\section{Analysis 2: The 2002-3 European Social Survey (ESS)}

Because the above analyses were conducted on data collected immediately before and after general elections, it is possible that the results are unusual. It is thus important to attempt to investigate the results in differing circumstances. The 2002-3 European Social Survey was chosen for these purposes. This ESS was conducted shortly prior to the start of the unpopular war in Iraq (the final set of interviews was conducted in February 2003, and the Iraq War began 20 March 2003) and outside of the context of a general election; it was also conducted prior to the large-scale influx of immigrants after the $2004 \mathrm{EU}$ enlargement. This survey does not contain a panel component, nor does it contain the wide array of questions on perceptions of government handling of specific policies, including perceptions of government handling of immigration or asylum, nor the entire range of questions about economic perceptions included in the BES. Thus we control for as many of the other predictors of political trust as possible, given these data limitations.

As with the BES analysis, we have combined the indicators of political trust to create a single 0-10 index (see Appendix B for question wording and scaling information). Unfortunately, no questions were asked pertaining to perceptions of government handling of immigration or asylum and so Hypotheses 2 and 3 cannot be 
investigated. Instead, we provide a simple analysis of the relationship between concern about the impact of immigration on the national community and political trust, controlling for interpersonal trust, voluntary participation, the electoral loser effect, perceptions of the national economy, perceptions of one's personal economic situation, age, education, income, gender, and left-right self-placement (see Appendix B for measures of these variables).

Table 3 presents the model for political trust in the British portion of the ESS. After controlling for the above-mentioned variables, the coefficients for concern about immigration achieve statistical significance, with a maximum impact of $1.5{ }^{53}$ It must be noted that in contrast to the BES results, the indicators of concern about the impact of immigration on culture and on jobs both achieve statistical significance, although the effect of the latter is half the size of the former. The fact that the indicator of concern about the economic impact of immigration is significant in the ESS analyses and not significant in either of the BES analyses could be a result of a few factors. First, the immigration items in the ESS are measured on 0 to 10 scales rather than 1 to 5 scales, as is the case with the BES items. Also, the question about the impact of immigration on jobs is more balanced in the ESS than in the case of the BES (see Appendices A and B), which may have drawn out more nuanced views, which in turn, affected responses to political trust questions differently. Finally, all items are measured within the same survey in the ESS. It is thus possible that the contemporaneous effect of concern about jobs illustrated in Table 3 dissipates over time, but the more consistent and powerful identity-related effect remains even after several months, as shown with the BES analysis. 
[Table 3 about here]

In order to confirm that these findings are not limited to the early part of the last decade, we have also investigated a model similar to that in Table 3 for the most recent round of the ESS (Round 4), which was fielded in Britain between September 2008 and January 2009 (analysis not shown). The results confirm that by 2008-9 concern about immigration was still having an impact on political trust. It is also important to note that we have analyzed the effect of concern about immigration and each of our three indicators of political trust separately in the ESS, as was the case with the BES analyses, and the results are similar to those reported here. That is, concern about immigration affected attitudes to parliament, the police, and politicians, indicating that the effects were not limited to elected institutions and politicians. Generally, then, these ESS results provide further confirmation of a connection between concern about the impact of immigration and political trust.

\section{Analysis 3: The 2002-3 ESS, An Instrumental Variables Approach}

It is possible that perceptions of political institutions explain concern about migration, rather than the reverse, as has been hypothesized in this paper; it is also possible that both of these perceptions respond to other factors which have been omitted from the models here. In addition, it is also possible that our measures of concern about immigration are measured with error. If these three problems exist, the OLS estimates reported above are biased and inconsistent. The extent and direction of the bias depends 
on the relative importance of each of these problems. If the main problem is that the direction of causality is reversed from what is hypothesized, OLS estimates are likely to overestimate the impact of concern about immigration. On the other hand, if random measurement error is the main problem, OLS estimates are likely to underestimate the impact of concern about immigration.

One solution to these problems is to use instrumental variables for potentially endogenous regressors-in this case, concern about immigration. An instrumental variables approach requires that we identify measures that are correlated with concern about immigration but otherwise uncorrelated with trust in institutions. That is, the instruments must have a significant partial correlation with concern about immigration controlling for all other exogenous determinants of political trust, while being uncorrelated with the error term. ${ }^{54}$

Thus, in order to further investigate whether causality runs in the direction hypothesized in this paper-i.e., whether concern about immigration does indeed affect perceptions of government institutions and politicians-we examine this relationship using an instrumental variables approach. Ideally, we would prefer to use this approach on the BES analyses but these surveys were not designed to understand attitudes to immigration and finding instruments for the immigration variables in the BES data sets was impossible. The ESS 2002-2003 questionnaire was, however, designed explicitly to investigate perceptions of immigration (amongst other things), and so finding adequate instruments for our indicators of attitudes to immigration is more likely with this survey.

Because of the difficulty of finding separate instruments for the two indicators of concern about migration used in the ESS analyses above, and because both indicators 
have statistically significant effects on political trust and are strongly correlated to one another (Pearson's r=0.62), we have combined the two to create a measure of general concern about the impact of immigration. We have then searched for instruments for this index, focusing first on variables that should theoretically be related to concern about immigration but are not directly related to political trust. One of the key instruments that we use for concern about immigration is contact with immigrants in the form of friendships. A considerable body of research indicates that this form of contact has consistent, strong effects on attitudes to outgroups, including immigrants and minorities. ${ }^{55}$ Feelings about having an immigrant as one's boss are also strong indicators of social distance and are significantly related to attitudes to immigration in the ESS. Other significant predictors of concern about immigration include expectations regarding qualifications for migration, namely that migrants speak the official language of the country, that they are committed to the way of life of the country, and that they be white. There is no theoretical reason to expect these variables to be directly related to political trust, but they ought to be (and are) related to general concerns about immigration. In order to further strengthen the instrument, we searched this data set for other variables that were strongly related to concern about immigration but not directly related to political trust. Several indicators of perceptions of where migrants come from were strongly related to the former but not to the latter, and these are incorporated as part of the instrument for concern about immigration (see Appendix C).

In order to investigate whether our instruments are significantly correlated with the potentially endogenous regressor, concern about immigration, we analyze the effect of the instruments on concern about immigration controlling for all exogenous variables 
that were included in the analysis in Table 3. The aim is to determine whether the instruments are significantly correlated with concern about immigration and have the anticipated signs, controlling for the included exogenous variables in the model. The results of this analysis are shown in Table 4. The coefficients on the instruments do indeed have the correct signs and are jointly significant. This is evaluated using the F statistic for the excluded instruments, which is 42.84 (significant at the $\mathrm{p} \leq .001$ level). This is clear evidence that the instruments are correlated with the endogenous regressor and thus satisfy the assumption that the selected instruments are relevant. ${ }^{56}$

[Table 4 about here]

Table 5 provides the OLS estimates from the model in Table 3 using the instrumental variable in place of concern about immigration. The results confirm those in previous sections: concern about immigration has a significant effect on political trust. We now turn to the conclusion to discuss the implications of these findings.

[Table 5 about here]

\section{Conclusion}

While concern about immigration has had clear effects on the political landscape of Europe via the changing nature of European party systems, this paper contends that the effects of such sentiment are also likely to be more subtle, operating via general feelings about the political system and the political community as a whole. The paper illustrates 
these effects in the specific case of Britain. Successive periods of immigration in Britain have been met with discomfort with being a country of immigration by ordinary citizens. Prior research points to the conclusion that discomfort about immigration is rarely related to personal economic self interest ${ }^{57}$ and instead stems from concern about the effect of immigration on the national community and the threats that immigrants are perceived to pose to this community, including those related to identity and economic resources. This study indicates that such concerns may not be inconsequential in Britain but may instead lead to a weakening of ties between the governed and the governors by seemingly undermining the very basis on which such connections were originally built — the common sense of shared myths, history, and culture. The potential consequences of reduced political trust are considerable because as noted above trust is crucial to effective policymaking, compliance with government regulations as well as engagement in civically moral behaviour. Political trust is also thought to be crucial to the representative relationship that lies at the heart of most democratic regimes. Although it is difficult to state definitively that our findings pertain to diffuse support in Britain, the evidence does point to the conclusion that across four different surveys (including the 2001 BES and 2008-9 ESS) and multiple indicators of political trust in the first decade of this century, feelings about the political system are very likely to have been affected by public perceptions of immigration and in 2005, by perceptions specifically of government handling of immigration. That is, the general findings are very likely to pertain to diffuse support.

The findings may be of considerable relevance to the growing body of research on the link between ethnic heterogeneity and trust. As noted above, the findings in this 
body of research are extremely mixed. The analysis here indicates that a potential missing component from these analyses is the perceptual component. As indicated in footnote 24 , it is well-established that perception often fails to mirror reality and so analyses that only incorporate actual levels of migration or diversity may fail to find much effect precisely because perceptions are so very different from reality. We contend here that it is the perceptions that are important in explaining political trust. They could be important in explaining social trust as well. That is, perceptions of the negative consequences of immigration or diversity could be eroding both political and social communities upon which modern European democracies have been built.

While the most immediate response to the argument and findings presented here may be the simple one of 'closing the gates', such a solution would not solve the problem raised by this paper. Whether British citizens like it or not, Britain has become a country of immigration and closing the gates would have no impact on the millions of immigrants and their families and descendants who are already in the country and consider it to be their home. Thus, perhaps an alternative solution is to revisit the construction of British identity, with the aim of more clearly establishing what British identity comprises and where the country's millions of foreigners fit within this construct. In addition, it is worth examining why concern about immigration is so much lower in some countries (e.g., Finland and Sweden) and whether those countries have adopted policies that might be relevant to British policymakers, such as rebuilding notions of community based on economic equality. At the very least, it must be recognized that immigration may be having long-term, unanticipated consequences for 
the functioning of the political system, which seem to require more open debate and discussion. 
Appendix A: Measurement of Variables in Analysis 1 (BES 2005)

Note that all BES 2005 Post-Election question wording is available at http://www.essex.ac.uk/bes/2005/Documents/BES05\%20Postwave\%20CAPI\%20questi onnaire.pdf, accessed 29 May 2009. The pre-election questionnaire is available at http://www.essex.ac.uk/bes/2005/Documents/PreCAPIMay31.pdf, also accessed 29 May 2009.

Dependent Variable and Control Variable: Political Trust ${ }_{t}$ and ${ }_{t-1}$ (pre- and postelection questionnaire)

Now, thinking about British political institutions like Parliament, please use the 0 to 10 scale to indicate how much trust you have for each of the following, where 0 means no trust and 10 means a great deal of trust.

And, how much do you trust the Parliament at Westminster? [bq20b]

And how much do you trust British politicians generally? [bq20c]

And how much do you trust the Police? [bq20d]

Cronbach's alpha for these items for the pre-election questionnaire is 0.78 and for the post-election questionnaire is 0.73 . For both questionnaires, the items load onto single factors, which explain 70.1 per cent of the variance (eigenvalue=2.1) in the pre-election questionnaire and 66.8 per cent in the post-election questionnaire (eigenvalue=2.0). Each set of items was thus combined by taking the average of the items, with the index ranging from $0-10$. 
Concern about the impact of immigration on the national community t-1 (preelection questionnaire)

Please indicate whether you agree or disagree with each of the following statements: Immigrants make Britain more open to new ideas and cultures. (Please take your answers from this card.) 1 Strongly agree; 2 Agree; 3 Neither agree nor disagree; 4 Disagree; 5 Strongly disagree [aq45b]

Immigrants take jobs away from people who were born in Britain. (Please take your answers from this card.) 1 Strongly agree; 2 Agree; 3 Neither agree nor disagree; 4 Disagree; 5 Strongly disagree $[\mathrm{aq} 45 \mathrm{~g}]$

The coding of the second item was reversed, and so the high value of 5 represents the strongest concern about the impact of immigration for both items.

\section{Perception of Government Handling of Immigration t-1 $_{\text {(pre-election questionnaire) }}$}

How well do you think the present government has handled each of the following issues? The number of asylum-seekers coming to Britain. 1 Very well; 2 Fairly well; 3 Neither well nor badly; 4 Fairly badly; 5 Very badly. [aq4c]

It must be noted that perceptions of government handling of the immigration issue is measured here with an indicator of perceptions of government handling of asylumseekers. This item has been chosen because it is the only available indicator of perceptions of government handling of an immigration-related issue in the BES data set. Although there are clear legal distinctions to be made between 'immigrants' and 'asylum 
seekers', in the case of Britain—as pointed out by Joppke—-there appears to be 'a zealous and instant equation of asylum seeking with immigration', ${ }^{58}$ with British asylum policy being structurally conflated with immigration control. ${ }^{59}$ Moreover, analyses of survey data indicate that the vast majority of citizens of the UK prefer that economic immigrants and asylum seekers be treated identically. For instance, in a Eurobarometer poll from Spring 2000 (EB 53), over 70 per cent of British respondents would suggest identical treatment for people coming from Muslim countries and Eastern Europe seeking work as they would for asylum seekers. ${ }^{60}$ This is true even when the question about asylum is posed in terms of individuals fleeing from serious internal conflict (e.g. civil war).

\section{Economic Evaluations t (post-election questionnaire)}

Now a few questions about economic conditions.

[Sociotropic retrospective evaluations] How do you think the general economic situation in this country has changed over the last 12 months? (Please take your answers from this card.) 1 Got a lot worse; 2 Got a little worse; 3 Stayed the same; 4 Got a little better; 5 Got a lot better [bq24]

[Sociotropic Prospective evaluations] How do you think the general economic situation in this country will develop over the next 12 months? (Please take your answers from this card.) 1 Get a lot worse; 2 Get a little worse; 3 Stay the same; 4 Get a little better; 5 Get a lot better [bq26]

[Pocketbook retrospective evaluations] How does the financial situation of your household now compare with what it was 12 months ago? (Please take your answers 
from this card.) 1 Got a lot worse; 2 Got a little worse; 3 Stayed the same; 4 Got a little better; 5 Got a lot better [bq23]

[Pocketbook prospective evaluations] How do you think the financial situation of your household will change over the next 12 months? (Please take your answers from this card.) 1 Get a lot worse; 2 Get a little worse; 3 Stay the same; 4 Get a little better; 5 Get a lot better [bq25]

\section{Perceived Political Performance $_{\mathfrak{t}}$ (Government Performance on Various Policy Dimensions) (post-election questionnaire)}

How well do you think the present government has handled each of the following issues? Crime in Britain [bq3a]

The National Health Service [bq3c]

The risk of terrorism in Britain [bq3d]

The economy in general [bq3e]

The level of taxation [bq3f]

Each of these questions is asked in turn, with respondents given the following response options: 1 Very well; 2 Fairly well; 3 Neither well nor badly; 4 Fairly badly; 5 Very badly. Cronbach's alpha for these items is 0.71 , and they all load onto a single factor, which explains 47.2 per cent of the variance in the items (eigenvalue=2.34). The items were thus combined into a single index by taking the average of the items, with the index ranging from 1-5. 


\section{Social Capital: Interpersonal trust ${ }_{\mathrm{t}}$ (post-election questionnaire)}

On balance, would you say that most people can't be trusted or that most people can be trusted? Please use the 0 to 10 scale to indicate your view. (Please take your answers from this card.) 0 Most people can't be trusted...10 Most people can be trusted [bq56] Do you think that most people you come into contact with would try to take advantage of you if they got the chance or would they try to be fair? Please use the 0 to 10 scale again, where 0 means would try to take advantage and 10 means would try to be fair. (Please take your answers from this card.) 0 Try to take advantage...10 Try to be fair [bq57]

The correlation (Pearson's r) between these two items was 0.61 and Cronbach's alpha was 0.75 . Thus, these two items were averaged to create a 0 to 10 scale, with 10 representing the highest level of interpersonal trust.

\section{Social Capital: Participation in Voluntary Activities (post-election questionnaire)}

Again, over the past few years, how active have you been in a voluntary organisation, like a local community association, a charity, or a sports club? 1 Very active; 2 Somewhat active; 3 A little active; 4 Not at all active/Not involved [bq52]

Note that the coding of this item has been reversed.

\section{Electoral Winning and Losing t (post-election questionnaire)}


Dummy variables were created for those who claimed to have voted for any party other than Labour, for the British National Party, and for those who did note vote. Thus, the comparison category is those who were the 'winners' (i.e., voted for the Labour Party).

\section{Education $_{t}$ (post-election questionnaire)}

Do you have any educational or work-related qualifications? 1 Yes; 2 No [bq82a] IF 'yes' at [bq82a] Taking your answers from this card, which is the highest qualification you have? Please just give me the number next to it. 1 Postgraduate degree; 2 First degree; 3 University/polytechnik diploma; 4 Teaching qualification; 5 Nursing qualification; $6 \mathrm{HNC/HND,} \mathrm{City \& Guilds} \mathrm{level} \mathrm{4,} \mathrm{NVQ/SVQ} \mathrm{4/5;} 7$ A level and equiv; 8 Scottish Higher and equiv; 9 ONC/OND, City\&Guilds level 3, NVQ/SVQ 3; 10 GCSE A*-C, CSE grade 1, O level grade A-C; 11 Scottish Standard grades, Ordinary bands; 12 GCSE D-G, CSE grades 2-5, O level D-E; 13 City\&Guilds level 2, NVQ/SVQ 2 and equiv; 14 City\&Guilds level 1, NVQ/SVQ 1 and equiv; 15 Clerical and commercial qualifications; 16 Recognized trade apprenticeship; 17 Youth training certificate, skill seekers; 18 Other technical, professional or higher qualification (WRITE IN)

This pair of questions was used to create dummy variables that would be equivalent to the UK education variable in the European Social Survey. The categories represented in that survey are as shown in Tables 2 and 3, with no qualifications as the omitted category.

\section{Age $_{\mathrm{t}}$ (post-election questionnaire)}


Now, a few questions about yourself and your background. What was your age last birthday? [bq77]

\section{Gender ${ }_{t}$ (post-election questionnaire)}

\section{INTERVIEWER TO OBSERVE AND RECORD: GENDER OF RESPONDENT}

1 Male; 2 Female [bq76]

This variable recoded such that female $=1$ and male $=0$.

\section{Income $_{t}$ (post-election questionnaire)}

Which of the letters on this card represents the total income of your household from all sources before tax - including benefits, saving and so on? Please just tell me the letter. (CARD J4 19) 1 Q; 2 T; 3 O; 4 K; 5 L; 6 B; 7 Z; 8 M; 9 F; 10 J; 11 D; 12 H; 13 P [bq84]

The showcard looks as follows:

\begin{tabular}{|c|c|c|}
\hline $\begin{array}{c}\text { Weekly income from all sources before } \\
\operatorname{tax}\end{array}$ & & $\begin{array}{c}\text { Annual income from all sources before } \\
\text { tax }\end{array}$ \\
\hline Less than $£ 96$ & Q & Less than $£ 5,000$ \\
\hline$£ 97-£ 192$ & T & $£ 5,001-£ 10,000$ \\
\hline$£ 193-£ 288$ & O & $£ 10,001-£ 15,000$ \\
\hline$£ 289-£ 384$ & K & $£ 15,001-£ 20,000$ \\
\hline$£ 385-£ 480$ & L & $£ 20,001-£ 25,000$ \\
\hline$£ 481-£ 577$ & B & $£ 25,001-£ 30,000$ \\
\hline$£ 578-£ 673$ & Z & $£ 30,001-£ 35,000$ \\
\hline$£ 674-£ 769$ & M & $£ 35,001-£ 40,000$ \\
\hline$£ 770-£ 865$ & F & $£ 40,001-£ 45,000$ \\
\hline$£ 866-£ 961$ & J & $£ 45,001-£ 50,000$ \\
\hline$£ 962-£ 1,153$ & D & $£ 50,001-£ 60,000$ \\
\hline$£ 1,154-£ 1,346$ & H & $£ 60,001-£ 70,000$ \\
\hline$£ 1,347$ or more & P & $£ 70,001$ or more \\
\hline
\end{tabular}


(BES post-election questionnaire from

http://www.essex.ac.uk/bes/2005/Documents/BES05\%20Postwave\%20CAPI\%20questi onnaire.pdf, accessed 29 May 2009, p. 88.)

\section{Left-right self-placement ${ }_{t}$ (post-election questionnaire)}

In politics, people sometimes talk about parties and politicians as being on the left or right. Using the 0 to 10 scale on this card, where the end marked 0 means left and the end marked 10 means right, where would you place yourself on this scale? (Please take your answers from this card.) 0 Left; 1 one; 2 two; 3 three; 4 four; 5 five; 6 six; 7 seven; 8 eight; 9 nine; 10 Right [bq39a]

\section{Approval of Britain's Involvement in Iraq t (post-election questionnaire)}

Please tell me whether you strongly approve, approve, disapprove, or strongly disapprove of Britain's involvement in Iraq.1 Strongly approve; 2 Approve; 3 Disapprove; 4 Strongly disapprove [bq42] (coding reversed).

\section{Appendix B: Measurement of Variables in Analysis 3 (ESS)}

Note that all ESS question wording is available at

http://www.europeansocialsurvey.org/, accessed 27 July 2010.

\section{Trust in Politicians and Political Institutions}

Please tell me on a score of 0-10 how much you personally trust each of the institutions I read out. 0 means you do not trust an institution at all, and 10 means you have complete 
trust. Firstly...READ OUT [country]'s parliament? the politicians? the police?

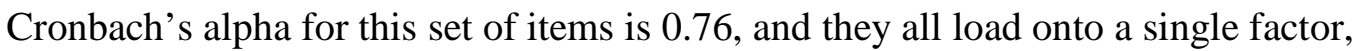
which explains 68.1 per cent of the variance in the items (eigenvalue=2.04). They were thus combined by taking the average of the items, with the index ranging from 0-10.

\section{Concern about the impact of immigration on the national community}

And would you say that [country]'s cultural life is generally undermined or enriched by people coming to live here from other countries? Cultural life undermined (0), Cultural life enriched (10).

Would you say that people who come to live here generally take jobs away from workers in [country], or generally help to create new jobs? Take jobs away (0) Create new jobs (10).

The coding of each of these items was reversed.

\section{Economic Evaluations}

[Sociotropic evaluations]: On the whole how satisfied are you with the present state of the economy in [country]? Still use this card. Extremely Dissatisfied (0), Extremely satisfied (10).

[Pocketbook evaluations] Which of the descriptions on this card comes closest to how you feel about your household's income nowadays? Living comfortably on present 
income (1) Coping on present income(2) Finding it difficult on present income(3) Finding it very difficult on present income(4).

\section{Social Capital: Interpersonal trust}

Generally speaking, would you say that most people can be trusted, or that you can't be too careful in dealing with people? Please tell me on a score of 0 to 10 , where 0 means you can't be too careful and 10 means that most people can be trusted.

Do you think that most people would try to take advantage of you if they got the chance, or would they try to be fair? Most people would try to take advantage of me (0) Most people would try to be fair (10).

Cronbach's alpha for these items is 0.69 and the Pearson's $r$ between them is 0.52 . The items were thus by combined by taking the average of the items, with the index ranging from 0 to 10.

\section{Social Capital: Participation in Voluntary Activities}

For each of the voluntary organisations I will now mention, please use this card to tell me whether any of these things apply to you now or in the last 12 months, and, if so, which. Respondents who claimed to participate in any of the organizations listed (or in one not listed) were given a code of 1 ; those who do not participate in any activities were given a code of 0 .

\section{Electoral Winning and Losing}


Dummy variables were created for respondents who claim to have voted for a party other than Labour or who did not vote; the comparison category is the 'winners', or Labour voters. Note that the survey did not include a separate category for the British National Party and so no dummy variable was created for this category.

\section{Other Controls}

Education: What is the highest level of education you have achieved? Please use this card. No qualifications (01) CSE grade 2-5/GCSE grades D-G or equivalent (02) CSE grade 1/O-level/GCSE grades A-C or equivalent (03) A-level, AS-level or equivalent (04) Degree/postgraduate qualification or equivalent (05) Other (WRITE IN) (06)

Age: In what year were you born?

Gender: coded by interviewer.

Income: Using this card, if you add up the income from all sources, which letter describes your household's total net income? If you don't know the exact figure, please give an estimate. Use the part of the card that you know best: weekly, monthly or annual income.

Left-right self-placement: In politics people sometimes talk of "left" and "right". Using this card, where would you place yourself on this scale, where 0 means the left and 10 means the right?.

\section{Appendix C: Measurement of Variables in Analysis 4 (Instrumental Variables)}

The following variables were used to construct the instrument for the analyses in Tables $4 \& 5$. 
Do you have any friends who have come to live in [country] from another country? Yes, several 1, Yes, a few 2, No, none at all, 3 [imgfrnd]

Now thinking again of people who have come to live in [country] from another country who are of the same race or ethnic group as most [country] people, how much would you mind or not mind if someone like this.... READ OUT...Not mind at all (0) ... Mind a lot (10) ... was appointed as your boss? Please use this card for your answer. [imdetbs]

Please tell me how important you think each of these things should be in deciding whether someone born, brought up and living outside [country] should be able to come and live here. Please use this card. How important should it be for them to .... be able to speak [country's official language(s)] [qfimlng]?... be white? [qfimwht ]... be wealthy? [qfimwlt ]... be committed to the way of life in [country]? [qfimcmt] Extremely unimportant (0)...Extremely important (10).

People come to live in [country] from other countries for different reasons. Some have ancestral ties. Others come to work here, or to join their families. Others come because they're under threat. Here are some questions about this issue.

Thinking of people coming to live in [country] nowadays from other countries, would you say that most are of the same race or ethnic group as the majority of [country] 
people (1) most are of a different race or ethnic group (2) or, is it about half and half (3)? [imgetn]. Category 3 was recoded to 1.5 .

Now thinking about people coming to live in [country] nowadays from other countries within Europe, would you say that most come from the richer countries of Europe (1), most come from the poorer countries of Europe (2), or, is it about half and half (3)? [eimgrpc] Category 3 was recoded to 1.5 .

And what about people who come to live in [country] nowadays from countries outside Europe, would you say that most come from the richer countries outside Europe (1), most come from the poorer countries outside Europe (2), or, is it about half and half (3)? [imgrpc] Category 3 was recoded to 1.5 . 
Table 1. Political Trust and Attitudes to Immigration, BES 2005 Results (Simple Models)

\begin{tabular}{|c|c|c|c|c|c|c|}
\hline & \multicolumn{3}{|c|}{ Model 1} & \multicolumn{3}{|c|}{ Model 2} \\
\hline & $b$ & SE & $\mathrm{p}$ & $\mathrm{b}$ & SE & $\mathrm{p}$ \\
\hline (Constant) & 3.31 & 0.15 & 0.000 & 1.99 & 0.34 & 0.000 \\
\hline Political trust $\mathrm{t}-1_{1}$ & 0.58 & 0.01 & 0.000 & 0.57 & 0.01 & 0.000 \\
\hline Concern about impact of immigration on culture $t-1$ & -0.09 & 0.03 & 0.001 & 0.38 & 0.14 & 0.005 \\
\hline Concern about impact of immigration on jobs $\mathrm{t}_{\mathrm{t}-1}$ & 0.00 & 0.03 & 0.906 & 0.10 & 0.12 & 0.404 \\
\hline $\begin{array}{l}\text { Government handling of immigration }{ }_{\mathrm{t}-1} \\
\text { Concern about culture }^{\star} \text { govt handling of }\end{array}$ & -0.14 & 0.03 & 0.000 & 0.19 & 0.08 & 0.022 \\
\hline immigration $_{\mathrm{t}-1}$ & & -- & & -0.11 & 0.03 & 0.000 \\
\hline 1 & & -- & & -0.02 & 0.03 & 0.376 \\
\hline Adjusted R2 & & 0.47 & & & 0.48 & \\
\hline SEE & & 1.21 & & & 1.20 & \\
\hline
\end{tabular}

Note: coefficients are unstandardized OLS coefficients; see the text of the paper and Appendix A for the description of the variables and question wording; $\mathrm{N}=2386$. 
Table 2. Political Trust Political Trust and Attitudes to Immigration, BES 2005 Results (Full Model)

(Constant)

Trust $\mathrm{t}-1_{1}$

Immigration attitudes

Concern about impact of immigration on culture $t-1$

Concern about impact of immigration on jobs $\mathrm{t}_{\mathrm{t}-1}$

Government handling of immigration $t-1$

Concern about culture*govt handling of immigration ${ }_{\mathrm{t}-1}$

Concern about jobs ${ }^{*}$ govt handling of immigration ${ }_{t-1}$

Economic Evaluations

Sociotropic retrospective

Sociotropic prospective

Pocketbook retrospective

Pocketbook prospective

Perceived Government handling of other issues

Social Capital

Interpersonal trust

Participation in voluntary activities

Electoral losers: Voted...

Party other than Labour

BNP

Did not vote

Other controls

Education

GCSE/O-level/CSE/NVQ1/NVQ2 or equiv

A-level/NVQ3 or equiv

NVQ4/NVQ5 or equiv

Degree/HNC/teacher training/nursing or equiv

PhD/DPhil or equiv

Age

Female

Household income

Left-right self-placement

Wales

Scotland

Approve of Britain's involvement in Iraq

Adjusted R squared

SEE

Note: coefficients are unstandardized OLS coefficients; see the text of the paper and Appendix A for the description of the variables and question wording; $\mathrm{N}=2386$.

$\begin{array}{ccc}\underline{\boldsymbol{b}} & \underline{\boldsymbol{S} E} & \underline{\underline{p}} \\ 2.28 & 0.42 & 0.000 \\ 0.45 & 0.02 & 0.000 \\ & & \\ 0.39 & 0.13 & 0.002 \\ 0.02 & 0.11 & 0.867 \\ 0.24 & 0.08 & 0.002 \\ -0.11 & 0.03 & 0.000 \\ 0.00 & 0.03 & 0.988\end{array}$

$\begin{array}{lll}0.08 & 0.03 & 0.029\end{array}$

$\begin{array}{lll}0.10 & 0.04 & 0.005\end{array}$

$\begin{array}{lll}0.02 & 0.03 & 0.561\end{array}$

$\begin{array}{lll}-0.07 & 0.03 & 0.043\end{array}$

$\begin{array}{lll}-0.48 & 0.04 & 0.000\end{array}$

$\begin{array}{lll}0.09 & 0.01 & 0.000\end{array}$

$\begin{array}{lll}-0.02 & 0.02 & 0.313\end{array}$

$\begin{array}{lll}-0.14 & 0.07 & 0.034\end{array}$

$\begin{array}{lll}-0.50 & 0.47 & 0.281\end{array}$

$\begin{array}{lll}-0.13 & 0.06 & 0.045\end{array}$

$\begin{array}{lll}-0.10 & 0.07 & 0.137\end{array}$

$\begin{array}{lll}0.06 & 0.09 & 0.523\end{array}$

$\begin{array}{lll}-0.07 & 0.10 & 0.507\end{array}$

$\begin{array}{lll}0.11 & 0.08 & 0.181\end{array}$

$\begin{array}{lll}0.08 & 0.12 & 0.497\end{array}$

$\begin{array}{lll}0.00 & 0.00 & 0.490\end{array}$

$\begin{array}{lll}0.08 & 0.05 & 0.092\end{array}$

$\begin{array}{lll}-0.01 & 0.01 & 0.483\end{array}$

$\begin{array}{lll}0.07 & 0.02 & 0.000\end{array}$

$\begin{array}{lll}-0.12 & 0.10 & 0.258\end{array}$

$\begin{array}{lll}-0.12 & 0.08 & 0.163\end{array}$

$\begin{array}{lll}0.10 & 0.03 & 0.001\end{array}$ 
Table 3. Political Trust and Attitudes to Immigration, ESS Results

(Constant)

$\begin{array}{lll}\underline{b} & \underline{\boldsymbol{S E}} & \underline{p} \\ 0.37 & 0.000\end{array}$

Immigration attitudes

Concern about impact of immigration on culture

$\begin{array}{lll}-0.10 & 0.02 & 0.000\end{array}$

Concern about impact of immigration on jobs

$-0.05 \quad 0.02$

0.014

\section{Economic Evaluations}

Satisfied with present state of economy in country

Difficult to live on present income

$\begin{array}{lll}0.27 & 0.02 & 0.000\end{array}$

\section{Social Capital}

Trust other people

$\begin{array}{lll}-0.07 & 0.06 & 0.206\end{array}$

Participation in voluntary activities

$\begin{array}{lll}0.23 & 0.02 & 0.000\end{array}$

Electoral losers: Voted...

Party other than Labour

$0.02 \quad 0.08$

0.819

Did not vote

$-0.31 \quad 0.10$

0.002

Other controls

Education

GCSE/O-level/CSE/NVQ1/NVQ2 or equiv

$-0.23$

0.10

0.024

A-level/NVQ3 or equiv

$\begin{array}{lll}0.13 & 0.11 & 0.241\end{array}$

NVQ4/NVQ5 or equiv

$0.09 \quad 0.15 \quad 0.545$

Degree/HNC/teacher training/nursing or equiv

$-0.14 \quad 0.15$

0.350

PhD/DPhil or equiv

$\begin{array}{ll}0.07 & 0.13\end{array}$

0.573

Age

$\begin{array}{ll}-0.16 & 0.44\end{array}$

0.713

Female

$0.00 \quad 0.00$

0.110

Household Income

$0.08 \quad 0.08$

0.336

Left-right self-placement

$\begin{array}{ll}-0.01 & 0.02\end{array}$

0.723

Scotland

$\begin{array}{lll}0.09 & 0.02 & 0.000\end{array}$

Wales

$\begin{array}{ll}-0.15 & 0.13\end{array}$

0.244

Adj R2

$\begin{array}{ll}-0.05 & 0.15\end{array}$

0.720

SEE

0.29

Note: coefficients are unstandardized OLS coefficients; see the text of the paper and Appendix C for the description of the variables and question wording; $\mathrm{N}=1707$. 
Table 4. Ordinary Least Squares Estimates of Concern about Immigration, ESS 2002-3

\begin{tabular}{|c|c|c|c|}
\hline Regressor & $\underline{b}$ & $\underline{\underline{S E}}$ & $\underline{p}$ \\
\hline No immigrant friends & 0.28 & 0.06 & 0.000 \\
\hline $\begin{array}{l}\text { Mind immigrant of different race/ethnicity from majority being } \\
\text { your boss }\end{array}$ & 0.13 & 0.02 & 0.000 \\
\hline Qualification for immigration: speak country's official language & 0.06 & 0.02 & 0.001 \\
\hline Qualification for immigration: committed to way of life in country & 0.12 & 0.02 & 0.000 \\
\hline Qualification for immigration: be white & 0.04 & 0.02 & 0.000 \\
\hline $\begin{array}{l}\text { Most immigrants to country of different race/ethnic group as } \\
\text { majority }\end{array}$ & 0.62 & 0.15 & 0.000 \\
\hline Immigrants from Europe: most from poor countries & 0.33 & 0.16 & 0.043 \\
\hline Immigrants from outside Europe: most from poor countries & 0.45 & 0.17 & 0.009 \\
\hline Standard Error of Regression & & 1.58 & \\
\hline R-squared & & 0.33 & \\
\hline Partial R-squared for excluded instruments & & 0.14 & \\
\hline F-statistic for test of excluded instruments & & 42.84 & \\
\hline F p-value & & 0.000 & \\
\hline
\end{tabular}

Note: coefficients are unstandardized OLS coefficients, controlling for all other exogenous predictors of political trust (see Table 5); see the text of the paper and Appendix $C$ for the description of the variables and question wording; $\mathrm{N}=1600$. 
Table 5. Political Trust and Attitudes to Immigration, ESS Results with Instrumental Variables

\begin{tabular}{|c|c|c|c|}
\hline & $\underline{b}$ & $\underline{S E}$ & $\underline{p}$ \\
\hline (Constant) & 2.94 & 0.41 & 0.000 \\
\hline $\begin{array}{l}\text { Immigration attitudes: Instrumental variable } \\
\text { Economic Evaluations }\end{array}$ & -0.14 & 0.05 & 0.004 \\
\hline Satisfied with present state of economy in country & 0.29 & 0.02 & 0.000 \\
\hline Difficult to live on present income & -0.08 & 0.06 & 0.163 \\
\hline \multicolumn{4}{|l|}{ Social Capital } \\
\hline Trust other people & 0.26 & 0.02 & 0.000 \\
\hline Participation in voluntary activities & 0.06 & 0.08 & 0.474 \\
\hline \multicolumn{4}{|l|}{ Electoral losers: Voted... } \\
\hline Party other than Labour & -0.34 & 0.10 & 0.001 \\
\hline Did not vote & -0.29 & 0.10 & 0.006 \\
\hline \multicolumn{4}{|l|}{ Other controls } \\
\hline \multicolumn{4}{|l|}{ Education } \\
\hline GCSE/O-level/CSE/NVQ1/NVQ2 or equiv & 0.13 & 0.12 & 0.257 \\
\hline A-level/NVQ3 or equiv & 0.06 & 0.15 & 0.699 \\
\hline NVQ4/NVQ5 or equiv & -0.15 & 0.16 & 0.334 \\
\hline Degree/HNC/teacher training/nursing or equiv & 0.18 & 0.13 & 0.180 \\
\hline PhD/DPhil or equiv & -0.07 & 0.44 & 0.869 \\
\hline Age & 0.00 & 0.00 & 0.080 \\
\hline Female & 0.09 & 0.08 & 0.257 \\
\hline Household Income & -0.02 & 0.02 & 0.457 \\
\hline Left-right self-placement & 0.09 & 0.03 & 0.000 \\
\hline Wales & -0.07 & 0.15 & 0.631 \\
\hline Scotland & -0.17 & 0.14 & 0.210 \\
\hline Adj R2 & & 0.29 & \\
\hline SEE & & 1.58 & \\
\hline
\end{tabular}

Note: coefficients are unstandardized OLS coefficients using instrumental variables; see the text of the paper and Appendices $B$ and $C$ for the description of the variables and question wording; $N=1619$. 
Figure 1. Immigration and Political Trust, Interactive Effect

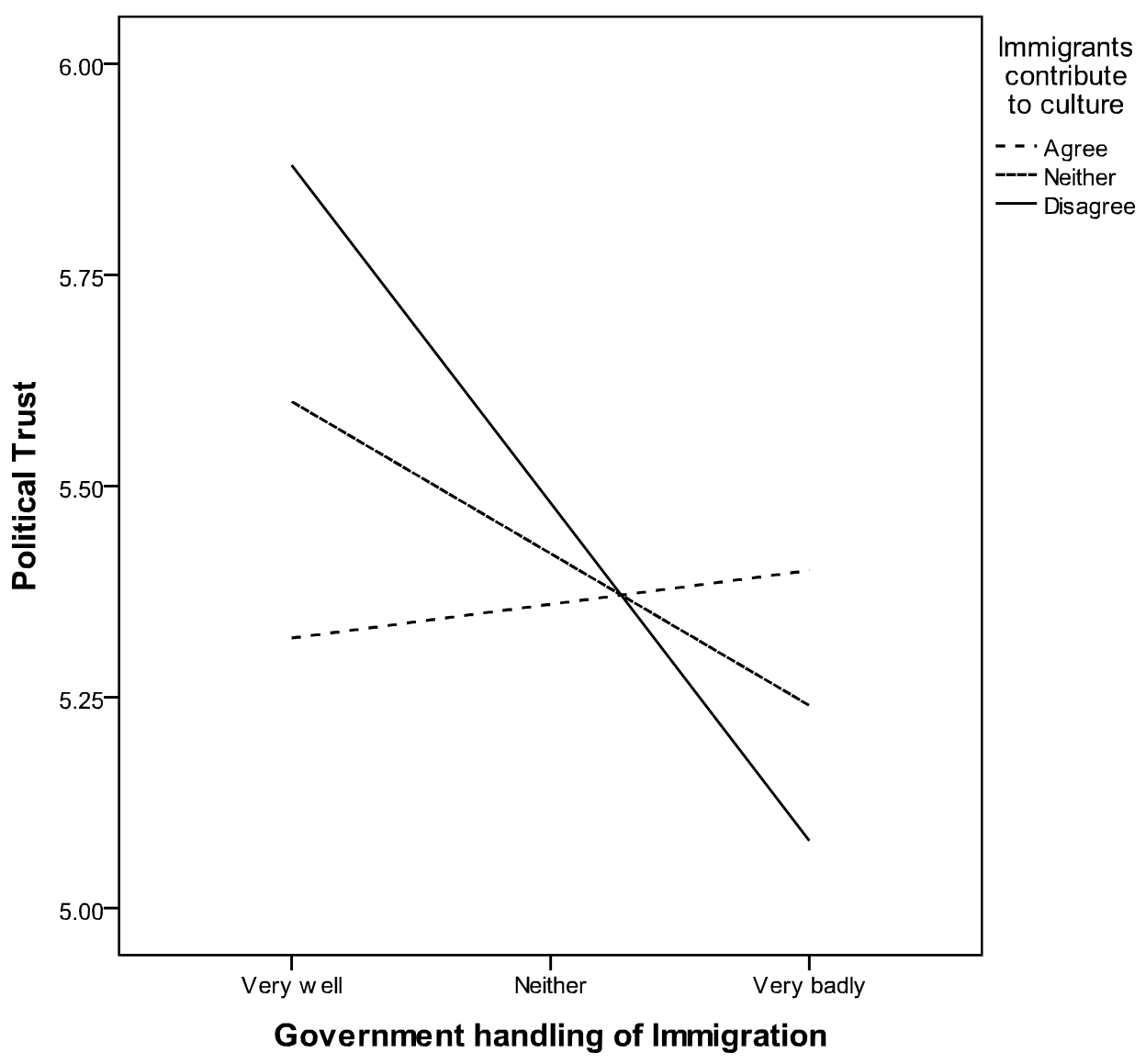

Note: figure was created by substituting high, medium, and low values for the immigration variables while holding all non-dichotomous variables at their means. All dichotomous variables (e.g., gender and region) were set to 0 . 
Figure 2. Marginal Effect of Concern about Immigration on Political Trust

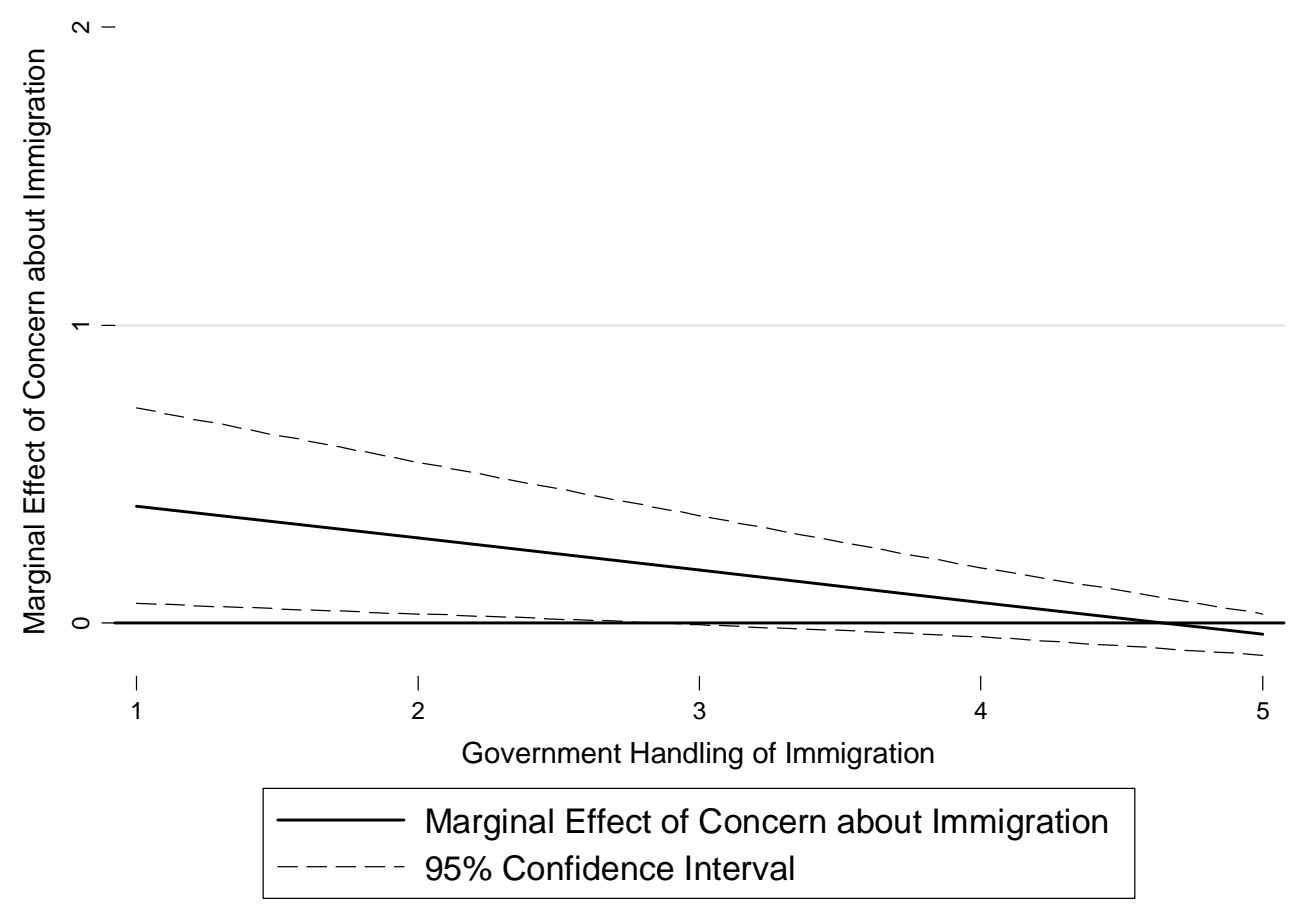

This method of displaying interactive effects is discussed in Thomas Brambor, William Roberts Clark, and Matt Golder, 'Understanding Interaction Models: Improving Empirical Analyses', Political Analysis 14 (2006), pp. 63-82; see also, http://homepages.nyu.edu/ mrg217/interaction.html\#code, last accessed 4 June 2010. 


\footnotetext{
${ }^{1}$ Note that Will Jennings' recent analysis ('The Public Thermostat, Political Responsiveness and Error-Correction: Border Control and Asylum in Britain, 1994-2007', British Journal of Political Science,
} 39 (2009), 847-70 ) indicates that changes in the administration of the asylum system are likely to be a direct result of shifts in public opinion regarding immigration, thus pointing to clear policy implications of concern about immigration in Britain.

${ }^{2}$ John T. Scholz and Mark Lubell, 'Trust and Taxpaying: Testing the Heuristic Approach to Collective Action', American Journal of Political Science, 42 (1998), .398-417; Sofie Marien and Marc Hooghe, 'Does political trust matter? An empirical investigation into the relation between political trust and support for law compliance', European Journal of Political Research, 50 (2011), 267-91; Natalia Letki, 'Investigating the Roots of Civic Morality: Trust, Social Capital, and Institutional Performance', Political Behavior, 28 (2006), 305-325.

${ }^{3}$ David Easton, 'An Approach to the Analysis of Political Systems', World Politics, 9 (1957), 383-40; Pippa Norris, ed, Critical Citizens (Oxford: Oxford University Press, 1999).

${ }^{4}$ Margaret Levi, 'A State of Trust', in Margaret Levi and Valerie Braithwaite, eds, Trust and Governance (New York: Russell Sage Foundation, 1998), pp. 77-101, at p. 80.

${ }^{5}$ Geoffrey Brennan, 'Democratic Trust: A Rational-Choice Theory View', in Margaret Levi and Valerie Braithwaite, eds, Trust and Governance , 197-217; Philip Pettit, 'Republican Theory and Political Trust', in Margaret Levi and Valerie Braithwaite, eds, Trust and Governance, 295-314.

${ }^{6}$ Arthur H. Miller, and Ola Listhaug, 'Political Parties and Confidence in Government: A Comparison of Norway, Sweden and the United States', British Journal of Political Science, 29 (1990), 357-86, p. 358.

${ }^{7}$ David Easton, 'An Approach to the Analysis of Political Systems', p. 391; see also Dankwart A. Rustow, 'Transitions to Democracy: Toward a Dynamic Model', Comparative Politics, 2 (1970), 337-363; David Miller (2000) also argues for the desirability of national identity in helping to create a more just society (see David Miller, 'Multiculturalism and the Welfare State: Theoretical Reflections', in Keith Banting and Will Kymlicka, eds, Multiculturalism and the Welfare State: Recognition and Redistribution in Contemporary Democracies [Oxford: Oxford University Press, 2006]).

${ }^{8}$ David Easton, A Systems Analysis of Political Life (NewYork: John Wiley and Sons, Inc., 1965). 
${ }^{9}$ This very question, of course, sparked a debate in the 1970 s over how to interpret increasing levels of expressions of distrust in politics in the U.S (Arthur Miller, 'Political Issues and Trust in Government', American Political Science Review, 68 (1974), 951-72; Jack Citrin, 'Comment', American Political Science Review, 68 (1974) , 973-88; Arthur Miller, 'Rejoinder', American Political Science Review, 68 (1974b), 989-1001).

${ }^{10}$ Russell Dalton, Democratic Challenges, Democratic Choices: The Erosion of Political Support in Advanced Industrial Democracies, Oxford: Oxford University Press (2004), pp. 58-60; Hans-Dieter Klingemann,. 'Mapping Political Support in the 1990s', in Pippa Norris (ed.), Critical Citizens, Oxford: Oxford University Press (1999), 31-56.

${ }^{11}$ Benedict Anderson, Imagined Communities: Reflections on the Origin and Spread of Nationalism (London: Verso Books, 1991).

${ }^{12}$ Ernest Gellner, Nations and Nationalism (Oxford: Blackwell, 1983); Eric J. Hobsbawm, Nations and Nationalism Since 1780: Programme, Myth, Reality (Cambridge University Press, 1992).

${ }^{13}$ Pierre van den Berghe, 'Race and Ethnicity: A Sociobiological Perspective', Ethnic and Racial Studies, 1 (1978), 401-11.

${ }^{14}$ Anthony D. Smith, National Identity (Reno: University of Nevada Press, 1991), p. 61.

${ }^{15}$ On the development of English and British identity, see Smith, National Identity; Liah Greenfeld, Nationalism: Five Roads to Modernity (Cambridge, MA: Harvard University Press, 1993); and Linda Colley, Britons: Forging the Nation, 1707-1837, 2nd ed, (New Haven, Conn. and London: Yale University Press, 1994).

${ }^{16}$ See Stephen Schulman, 'Challenging the Civic/Ethnic and West/East Dichotomies in the Study of Nationalism', Comparative Political Studies, 35 (2002), 554-85.

${ }^{17}$ Henri Tajfel, 'Experiments in Intergroup Discrimination', Scientific American, 223 (1970), 96-102; John C. Turner, 'Towards a Cognitive Redefinition of the Social Group', in Henri Tajfel, ed, Social Identity and Intergroup Relations (Cambridge: Cambridge University Press, 1982), pp. 15-40; John C. Turner, 'Social Categorization and the Self-Concept: A Social Cognitive Theory of Group Behavior', Advances in Group Processes 2 (1985), 77-122. 
${ }^{18}$ Lincoln Quillian, 'Prejudice as a Response to Perceived Group Threat: Population Composition and Anti-Immigrant and Racial Prejudice in Europe', American Sociological Review, 60(1995), 586-611; Paul M. Sniderman, Louk Hagendoorn and Markus Prior, 'Predisposing Factors and Situational Triggers: Exclusionary Reactions to Immigrant Minorities', American Political Science Review, 98(2004), 35-49; Joel S. Fetzer, Public Attitudes toward Immigration in the United States, France, and Germany (Cambridge: Cambridge University Press, 2000).

${ }^{19}$ It must be noted that even in the U.S. there tend to be perceived limitations regarding who are acceptable migrants, as the modern debates about migration from Mexico have indicated (and previous debates about migrants from Ireland, Italy, Poland and many other countries indicate—see Rita J. Simon, 'Old Minorities, New Immigrants: Aspirations, Hopes, and Fears', Annals of the American Academy of Political and Social Science, 530 (1993), 61-73).

${ }^{20}$ David Easton, 'An Approach to the Analysis of Political Systems', p. 391; see also Dankwart A. Rustow, 'Transitions to Democracy: Toward a Dynamic Model', Comparative Politics, 2 (1970), 337-363; David Miller (2000) also argues for the desirability of national identity in helping to create a more just society (see David Miller, 'Multiculturalism and the Welfare State: Theoretical Reflections', in Keith Banting and Will Kymlicka, eds, Multiculturalism and the Welfare State: Recognition and Redistribution in Contemporary Democracies [Oxford: Oxford University Press, 2006]).

${ }^{21}$ Christopher J. Anderson and Aida Paskeviciute, 'How ethnic and linguistic heterogeneity influence the prospects for civil society: A comparative study of citizenship behavior', Journal of Politics, 68 (2006), 783-802; Alberto F. Alesina, and Eliana La Ferrara, 'Participation in Heterogeneous Communities', Quarterly Journal of Economics, 115 (2000), 847-904; Dora L. Costa and Matthew E. Kahn, 'Civic Engagement in Heterogeneous Communities', Perspectives on Politics, 1 (2003), 103-112; Dietlind Stolle, Stuart Soroka and Richard Johnston, 'When Does Diversity Erode Trust? Neighborhood Diversity, Interpersonal Trust and the Mediating Effect of Social Interactions', Political Studies, 56(2008), 57-75; Natalia Letki, 'Does Diversity Erode Social Cohesion? Social Capital and Race in British Neighbourhoods', Political Studies, 56(2008), 99-126; Marc Hooghe, Tim Reeskens, Dietlind Stolle, Ann Trappers, 'Ethnic Diversity and Generalized Trust: A Cross-National Multilevel Study', Comparative Political Studies, 42 (2009), 198-223; Patrick Sturgis, Ian Brunton-Smith, Sanna Read, and Nick Allum, 
'Does ethnic diversity erode trust?: Putnam's 'hunkering-down' thesis reconsidered', British Journal of Political Science. 41 (2011), 57-82.

${ }^{22}$ Martin Gilens, Why Americans Hate Welfare: Race, Media, and the Politics of Anti-Poverty Policy (Chicago: University of Chicago Press, 1999); James Habyarimana, Macartan Humphreys, Daniel N. Posner and Jeremy M Weinstein, 'Why Does Ethnic Diversity Undermine Public Goods Provision?', American Political Science Review 101(2007), 709-25.

${ }^{23}$ Smith, National Identity, p. 12.

${ }^{24}$ In some contexts it might be appropriate to also try to incorporate indicators of numbers of immigrants; however, in the British case we assume that perceptions about immigration are generally determined more by national-level phenomena such as overall (national) levels of migration to Britain and national media presentation of immigration and immigrants. Thus while certain areas of the UK have been affected more by immigration (see for instance, Julie Smith, 'Towards Consensus? Centre-Right parties and immigration policy in the UK and Ireland', in Tim Bale, ed, Immigration and Integration Policy in Europe: Why Politics-and the Centre-Right-Matter (London: Routledge 2009), pp. 101-17, at p. 108), detecting local differences in the relationship between concern about immigration and political trust is likely to be difficult. In addition, we are not able to incorporate information about contact with immigrants, which has a powerful mediating effect on perceptions of immigrants and immigration (see, for instance, Thomas Pettigrew, 'Intergroup Contact Theory', Annual Review of Psychology 49, (1998), 65-85). Moreover, exploratory analyses of the 2005 BES data set indicates that local levels of migration, ethnic composition, and percent Muslim are very weakly related to perceptions of migration. Analyses of other attitudinal data in the UK also indicates that these often fail to be connected to objective indicators (see, for instance, Peter Taylor-Gooby and Charlotte Hastie, 'Support for state spending: has New Labour got it right?', in Alison Park et al, eds, British Social Attitudes $19^{\text {th }}$ Report (London, Sage, 2002), pp. 76-97, at p. 88). This phenomenon of misperception is not, of course, limited to the UK, particularly in the case of estimating numbers of immigrants (John Sides and Jack Citrin, 'European opinion about immigration: the role of identities, interests and information,' British Journal of Political Science 37(2007), 477-504).

${ }^{25}$ David Butler and Donald Stokes, Political Change in Britain: forces shaping electoral choice (London : Macmillan, 1969), p. 303. 
${ }^{26}$ Eurobarometer 47.1 Images of Switzerland, Education throughout life, Racism, and Patterns of Family Planning and Work Status, March-April 1997.

${ }^{27}$ Lauren McLaren and Mark Johnson, 'The Rising Tide of Anti-Immigrant Sentiment in Britain ', in Alison Park et al, eds British Social Attitudes 21st report 2004 (London: Sage Publications, 2004), p. 172; Alison Park et al., eds. British Social Attitudes 26th report (London: Sage Publications, 2010).

${ }^{28}$ http://www.ipsos-mori.com/researchpublications/researcharchive/poll.aspx?oItemId=53\&view=wide, consulted 24 May 2010

${ }^{29}$ See Transatlantic Trends: Immigration Key Findings 2009 at http://www.gmfus.org/trends/immigration/doc/TTI_2009_Key.pdf; and Transatlantic Trends: Immigration Topline Data 2008 at http://www.gmfus.org/trends/immigration/doc/TTI_2008_Topline.pdf, consulted 24 May 2010.

${ }^{30}$ Schulman, 'Challenging the Civic/Ethnic and West/East Dichotomies in the Study of Nationalism', pp. $566,569,570,576,577$.

${ }^{31}$ Lauren McLaren and Mark Johnson, 'Resources, Group Conflict, and Symbols: Explaining AntiImmigration Hostility in Britain', Political Studies, 55 (2007), 709-732; Clive D. Field, 'Islamophobia in Contemporary Britain: The Evidence of the Opinion Polls, 1988-2006', Islam and Christian-Muslim Relations, 18: 4 (2007), 447-77.

${ }^{32}$ The analysis conducted in this paper is on data from prior to the 2010 election, and so we omit discussion of the Liberal Democrat position on this issue.

${ }^{33}$ Randall Hansen, Citizenship and Immigration in Post-war Britain: The Institutional Origins of a Multicultural Nation (Oxford: Oxford University Press, 2000); Christian Joppke, Immigration and the Nation-State: The United States, Germany and Great Britain (Oxford: Oxford University Press, 1999). Although the Labour Party in the 1997-2005 period appeared to be far more favourable to increased immigration, the fall-out from the unexpectedly large-scale migration from Central and Eastern Europe after the 2004 enlargement of the EU seems to have propelled the creation of more restrictive immigration legislation, using a points-based system to discourage low-skilled migration to the UK (see http://news.bbc.co.uk/1/hi/uk_politics/7269790.stm, http://news.bbc.co.uk/1/hi/uk_politics/7904393.stm, or http://news.bbc.co.uk/1/hi/uk_politics/7951721.stm, all accessed 14 July 2009). At the time of the 
fieldwork for the surveys used in this analysis, it was not entirely clear that immigration policies of Conservative governments would be that different from those of the Labour government (see, for instance, http://news.bbc.co.uk/1/hi/uk_politics/7677962.stm, accessed 14 July 2009), although the recent proposal to introduce caps on immigration is clearly more restrictive than Labour's general approach to the issue. In the 2010 election campaign, however, Labour, the Conservatives and the Liberal Democrats all stated their desire for strong restrictions on immigration (see Julie Smith 'Towards Consensus?', for an overview of party approaches to immigration in the UK prior to 2009).

${ }^{34}$ For instance, in 2002, then Home Secretary Blunkett suggested that immigrants speak English in their own homes, advised Asians to stop making arranged marriages in their home countries and make them within the UK instead and compared Muslim forced marriages with practices of medieval England (see The Times, 16 September 2002, p. 1g, 1 June 2002, p. 2e, and 15 January 2002, p. 8f).

${ }^{35}$ On the cross-time positions of political parties on immigration and race see Joppke, Immigration and the Nation-State; James Hampshire, Citizenship and Belonging: Immigration and the Politics of Demographic Governance in Postwar Britain (Houndsmills: Palgrave Macmillan, 2005); Kathleen Paul, Whitewashing Britain: Race and Citizenship in the Postwar Era (Ithaca, NY: Cornell University Press, 1997); in the 2005 general election, Conservative leader Michael Howard appeared to attempt to distance himself and his party somewhat from this issue-despite incorporating it as an important part of the party's platform—by arguing that immigration was only one of its five important issues, and some moderates in the Conservative party were 'annoyed' at the prominence given to immigration by some of the Conservative candidates (see Dennis Kavanagh and David Butler, The British general election of 2005 (Basingstoke: Palgrave Macmillan, 2005), p. 76; Julie Smith, ‘Towards Consensus?’).

On the cohesion of the parties on this issue, Whiteley et al (Paul Whiteley, Patrick Seyd, Jeremy John Richardson, True Blues: the Politics of Conservative Party Membership (Oxford: Oxford University Press, 1994)) find that 91 per cent of the members of the Conservative Party believe immigration controls should be tightened, compared to 70 per cent of Labour Party members. In addition, although there is 'tough talk' on immigration by many of the Labour Party's leaders as noted above and several prominent Labour Party members, other Labour MPs believe highlighting such problems only gives succor to public racist sentiments and to the BNP. We are grateful to an anonymous reviewer for pointing this out. 
${ }^{36}$ Andrew Geddes and Jonathan Tonge, Britain Decides: The UK General Election 2005 (Basingstoke: Palgrave, 2005); Kavanagh and Butler, The British General Election of 2005; Harold Clarke, David Sanders, Marianne Stewart and Paul Whiteley, 'Taking the Bloom off New Labour's Rose: Party Choice and Voter Turnout in Britain, 2005', Journal of Elections, Public Opinion and Parties, 16 (2006), 3-36. ${ }^{37}$ Previous drafts of this paper have discussed the nature of national identity in the UK but this material has been removed from this draft due to space limitations. It is important to note that the conclusion from that discussion was that although many scholars had previously argued that British identity was mostly civic in nature, in fact, there are strong civic, ethnic, and cultural components, the latter two of which make inclusiveness toward immigrants extremely difficult. The earlier draft also discussed Scotland and Wales in relation to British identity. These discussions of British identity from the earlier version of the paper are available from the authors upon request.

${ }^{38}$ Edward N. Muller, 'A Test of a Partial Theory of Potential for Political Violence', American Political Science Review, 66 (1972), 928-59, p. 943; Max Kaase, 'Interpersonal Trust, Political Trust and NonInstitutionalised Political Participation in Western Europe', West European Politics, 22 (1999), 10-12; Klingemann, 'Mapping Political Support in the 1990s', p. 37.

${ }^{39}$ Harold D. Clarke, Nitish Dutt, and Allan Kornberg, 'The Political Economy of Attitudes towards Polity and Society in Western European Democracies', Journal of Politics, 55 (1993), 998-1021; Christopher J. Anderson, and Christine A. Guillory, 'Political Institutions and Satisfaction with Democracy: A CrossNational Analysis of Consensus and Majoritarian Systems', American Political Science Review, 91 (1997), 66-81; Brad Lockerbie, 'Economic Dissatisfaction and Political Alienation in Western Europe', British European Journal of Political Science, 23 (1993), 281-93.

${ }^{40}$ Miller and Listhaug 'Political Parties and Confidence in Government'; Arthur H. Miller and Ola Listhaug, 'Political Performance and Institutional Trust', in Pippa Norris, ed, Critical Citizens: Global Support for Democratic Governance (Oxford: Oxford University Press, 1999) pp. 204-16; Kenneth Newton, 'Political Support: Social Capital, Civil Society and Political and Economic Performance', Political Studies, 54 (2006), 846-864. 
${ }^{41}$ John Brehm and Wendy Rahn, 'Individual-Level Evidence for the Causes and Consequences of Social Capital', American Journal of Political Science, 41 (1997), 999-1023; Sonja Zmerli and Ken Newton, ‘Social Trust and Attitudes Toward Democracy’, Public Opinion Quarterly 72(2008), 706-24.

${ }^{42}$ Anderson and Guillory 'Political Institutions and Satisfaction with Democracy'; Christopher J. Anderson and Andrew J. LoTempio, 'Winning, losing and political trust in America', British Journal of Political Science, 32 (2002), 335-51.

${ }^{43}$ Interviews were conducted face-to-face in England, Wales, and Scotland; see Mark Johnson, Katarina Thomson and Shaun Scholes, British Election Study 2005 Technical Report March 2007, P2448/P2474/P2517; available at http://www.essex.ac.uk/bes/2005/Survey\%20Documents/bes\%20technical\%20report\%20plus\%20internet \%202007.pdf, accessed 28 July 2009; note that the pre-election British weight has been applied (see pp. 20-22 of the report).

${ }^{44} \mathrm{We}$ are limited to these two items by question availability in the $2005 \mathrm{BES}$; however, the two items do capture the main threats thought to be posed by immigration, namely cultural and economic threat (e.g., Sniderman, Hagendoorn and Prior, 'Predisposing Factors and Situational Triggers').

${ }^{45}$ Anderson and Guillory, 'Political Institutions and Satisfaction with Democracy'; Anderson and LoTempio, 'Winning, Losing and Political Trust in America'; Anderson and Paskeviciute. 'How Ethnic and Linguistic Heterogeneity Influence the Prospects for Civil Society'.

${ }^{46}$ Robert Rohrschneider, 'Institutional Quality and Perceptions of Representation in Advanced Industrial Democracies', Comparative Political Studies, 38 (2005), 850-74.

${ }^{47}$ Job category had very little effect and has been omitted from the analysis. Also, note that ethnic minorities have been removed from all of the analyses, including those in Table 1.

${ }^{48}$ Note that the BES contains an indicator of perceptions of government handling of Iraq in the preelection questionnaire, but when added to the regression below it is statistically insignificant.

${ }^{49}$ Actual values of concern about immigration and perceptions of government handling of immigration have been inserted into the equations in Table 2 while the values of other variables are as follows. Lagged political trust has been set to 5 , which is the midpoint of the scale; all of the indicators of economic perceptions have been set to 3 (stayed the same); perceptions of government handling of non-immigration 
policies have been set to the centre point of 3; interpersonal trust has been set to its midpoint of 5;

voluntary participation has been set to its midpoint of 2.5 ; all loser dummies are set to 0 and so the results represent a Labour voter; education dummies are also set to 0 , with the results representing those for individuals with no qualifications; age is set to 50, which is the mean and median of this variable; gender is set to 0 , which is the category for males; household income set to 7, the midpoint on the income scale; left-right self-placement is set to 5; approval of involvement in Iraq has been set to 2.5; the Scotland and Wales country dummies are set to 0, thus the equation represents respondents living in England. ${ }^{50}$ This method of displaying interactive effects is discussed in Thomas Brambor, William Roberts Clark, and Matt Golder, 'Understanding Interaction Models: Improving Empirical Analyses', Political Analysis 14 (2006), 63-82; see also, http://homepages.nyu.edu/ mrg217/interaction.html\#code, last accessed 4 June 2010.

${ }^{51}$ The survey questions in the 2001 BES specifically ask about respect for parliament, politicians, and the police rather than about trust or confidence.

${ }^{52}$ Although it is difficult to determine why this might be the case in any definitive way, it is likely that the 9-11 attacks in the United States—which took place after the 2001 British general election—and the 2004 EU enlargement, with the subsequent influx of migrant workers from Central and Eastern Europe and government underestimation of these numbers were fairly important by 2005 . In addition, the immigration issue was specifically raised by the Conservative Party in the 2005 general election and perhaps more crucially was the focus of considerable media attention, which may have affected the results for this survey. At the same time, however, it is also important to note that concern about the impact of immigration on national culture was having an effect on perceptions of parliament, politicians and the police even in 2001 and even after controlling for all of the above-mentioned predictors. It is also important to note that the 2001 BES also took place before the results of the 2001 census were announced in September 2002- that is, prior to the official report indicating that net migration was increasing under the Labour government. Thus, the 2001 results reported above are unlikely to be short-term responses to sudden new information about levels of migration. 
${ }^{53}$ The maximum effect of perceptions that immigrants undermine national culture on political trust is 1.0 while the maximum impact of perceptions that immigrants take jobs from natives is 0.5 , for a combined total of 1.5 (with political trust and perceptions of immigrants both measured on a 0-10 scale).

${ }^{54}$ Matthew Gabel and Kenneth Scheve, 'Estimating the Effect of Elite Communications on Public Opinion Using Instrumental Variables', American Journal of Political Science, 51 (2007), 1013-28, p. 1020.

${ }^{55}$ For a review of the findings related to the contact hypothesis, see Jared B. Kenworthy, Rhiannon N. Turner, Miles Hewstone, and Alberto Voci, 'Intergroup Contact: When Does it Work, and Why?', in John F. Dovidio, Peter Samuel Glick, and Laurie A. Rudman, eds, On the Nature of Prejudice: Fifty Years after Allport (Blackwell Publishing Ltd.: Oxford, 2005), pp. 278-92.

${ }^{56}$ Gabel and Scheve, 'Estimating the Effect of Elite Communications', pp. 1021-22.

Although significant, the correlation between the instruments and concern about immigration is somewhat weak, which may bias the instrumental variables estimates toward the corresponding OLS estimates. Concern about the strength of the instruments for perceptions of immigration may be mitigated by examining the reduced form regression of political trust on the instruments and the exogenous variables. These estimates are proportional to the coefficient of interest and are unbiased even if the instruments are weak and so indicate the sign of the coefficient of interest. The results of this regression show negative and statistically significant coefficients for the instruments 'No immigrant friends; and 'Qualification for immigration: committed to way of life in country', and 'Qualification for immigration: committed to way of life in country', with the signs in the correct direction. These results indicate that the coefficient for concern about immigration is negative as we report in the instrumental variable results below (see Gabel and Scheve, 'Estimating the Effect of Elite Communications', p. 1022, fn 16 for a similar approach to the problem of weak instruments).

${ }^{57}$ Sniderman, Hagendoorn and Prior. 'Predisposing Factors and Situational Triggers'; Quillian, 'Prejudice as a Response to Perceived Group Threat'; McLaren and Johnson, 'Resources, Group Conflict, and Symbols'.

${ }^{58}$ Christian Joppke, 'Asylum and State Sovereignty: A Comparison of the United States, Germany, and Britain', Comparative Political Studies, 30 (1997), 259-98, p. 264. 
${ }^{59}$ Joppke, ‘Asylum and State Sovereignty', p. 285.

${ }^{60}$ Poll available for online analysis at http://zacat.gesis.org/webview/index.jsp, accessed 20 July 2009. 